\title{
Canonicidade silábica e aprendizagem da escrita
}

\author{
Alvarenga, D. \& Oliveira, M. A. \\ Universidade Federal de Minas Gerais
}

\section{Abstract}

In this paper we examine the influence of the syllable structure of spoken Portuguese on the acquisition of written forms. Our main hypothesis is that spoken language offers a first model for the construction of written forms and so, by identifying the syllabic coda as a point of instability in spoken Portuguese, since it is subject to many phonological processes, we may predict that students will also present writing variations exactly at these same points. Our investigation takes into account structural as well as non-structural factors and we conclude that there is a strong correlation between instability in the syllabic coda and variation in their weitten representation. 


\section{INTRODUÇÃO}

sílaba é, possivelmente, um dos elementos mais analisados
na fonologia atual. Podemos dizer que ela ocupa um lugar
privilegiado em todos os trabalhos de Fonologia Autosegmental que se têm produzido atualmente. Várias dessas pesquisas têm afirmado que a análise fonológica se enriquece enormemente em adequação empírica quando se considera o nível silábico. Uma série de fenômenos (como acréscimos ou apagamentos de vogais, apagamentos de consoantes, transformações de vogais e de consoantes, entre outros) são melhor explicados no quadro de uma fonologia que postula, no seu quadro teórico, um nível silábico, intermediário entre o nível da palavra e o nível do segmento.

Adotando um quadro teórico que defende a importância da sílaba, vamos analisar neste artigo a influência da instabilidade das consoantes de final de sílaba do português na produção escrita de aprendizes da escola fundamental. Além de atestar esta instabilidade estrutural de final de sílaba (coda), queremos, também, avaliar a influência de alguns fatores extra-lingüísticos na ocorrência de variações de escrita ${ }^{1}$ desses mesmos aprendizes. Assim, escolhemos, como possíveis fatores condicionantes o nível de escolaridade, a classe social, o método de aprendizagem e o sexo.

Elegendo o fenômeno da aprendizagem da ortografia, não estamos querendo esquecer os diversos elementos de natureza diferente que aí interferem. A aprendizagem da língua escrita pressupõe, basicamente, um processo no qual intervêm, necessária e simultaneamente, três elementos distintos e fundamentais: (A) um sistema sonoro - as representações fonológicas da língua; (B) um 
sistema gráfico - as representações ortográficas; (C) um indivíduo que (re)constrói as relações entre A e B.

Estaremos, no presente trabalho, centrando nossos esforços no sentido de aprofundar o item (A) - o sistema fonológico do português - e suas interferências no $(\mathrm{C})$ - o indivíduo quando este entra em contato com o (B) - sistema ortográfico do português.

No que concerne ao sistema fonológico, algumas idéias devem ser ressaltadas. Os elementos sonoros de uma língua, os fonemas, devem ser analisados não só como entidades isoladas (com características articulatórias e acústicas específicas), mas também como entidades constitutivas de um sistema. Estudar o sistema fonológico significa, pois, num primeiro momento, descrever os fonemas, indicar como eles são articulados e percebidos. Este aspecto já é bem analisado na literatura lingüística: o que é um som vocálico e um som consonantal; diferenças articulatórias entre um e outro; altura da língua no momento da articulação, os modos e pontos de articulação, a função das fossas nasais e das cordas vocais. Estudar o sistema fonológico significa também, num segundo momento, compreender outros níveis deste sistema: a maneira pela qual os fonemas se organizam em unidades superiores, inicialmente em sílabas (e este é o nosso objetivo básico no presente trabalho), em seguida em palavras.

Ao final dessa introdução, cabem algumas perguntas básicas no que se refere ao nível de organização dos fonemas em sílabas: como é que os fonemas se organizam em sílabas? Que tipos de sílabas podem ser mais ou menos esperados numa língua? Existe algum princípio fonológico que controla a ocorrência dos fonemas dentro da sílaba e das sílabas dentro da palavra? O conhecimento e o aprofundamento do nível silábico nos ajudam a compreender melhor o processo de aprendizagem da língua escrita? No sentido de caracterizar o sistema fonológico do português, as nossas colocações e nossas análises estarão tentando responder essas perguntas. 


\section{O QUADRO TEÓRICO DA ANÁLISE}

Na literatura fonológica, há duas teorias gerais sobre a sílaba, a saber, a teoria dos constituintes e a teoria da sonoridade. De acordo com a teoria dos constituintes, a sílaba é uma estrutura bierárquica de posições puras que pode ser representada conforme o esquema abaixo:

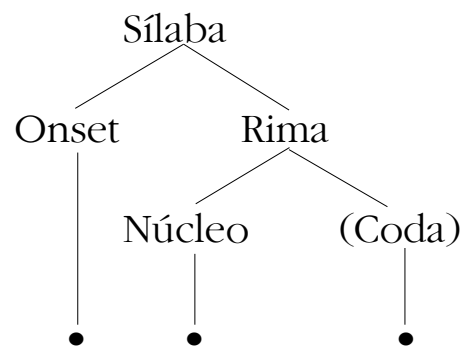

Num nível superior, a sílaba será uma estrutura constituída de um onset e de uma rima. A rima, por sua vez, é constituída de um núcleo seguido, opcionalmente, de uma coda. Os pontos abaixo dos rótulos indicam que o onset, o núcleo e a coda não são, a princípio, segmentos ou fonemas, mas posições puras que podem ser preenchidas ou não no nível segmental. ${ }^{2}$ Aceitamos, como princípio geral, que toda sílaba fonológica é constituída de uma posição 'onset' e de uma posição 'rima'. Isso não significa que toda sílaba em português tenha que ter, por exemplo, um onset. O que estamos sugerindo é que a posição de onset, necessária do ponto de vista fonológico, pode não ser preenchida no nível fonético, o que faz criar aí um ponto de instabilidade estrutural, pois o ideal seria ter, no nível segmental, uma sílaba com este onset preenchido. Esta instabilidade estrutural é a base para se postular a hipótese de que sílabas com onset não preenchido são focos mais prováveis de variações na língua do que aquelas que têm onset preenchido.

A partir da noção de "autorização" (licencing), podemos definir para o português um conjunto de traços fonológicos em cada posição. O nódulo silábico (S) autoriza todos os traços consonantais distintivos da língua na posição de onset e todos os traços vocálicos 
distintivos da língua na posição de rima. Isto significa que todas as consoantes da língua podem aparecer na posição de onset. O nódulo C (coda) só autoriza um número muito restrito de traços distintivos.

A partir dessa hierarquização e do conceito de autorização, podemos, do ponto de vista cognitivo, defender, por exemplo, a existência de posições consonantais fortes e fracas na sílaba: o onset é a posição forte, ou a posição consonantal estável; a coda é a posição fraca, ou posição consonantal instável. Dessa maneira, a coda pode ser interpretada como um lugar de virtuais variações na língua, o "lugar fonológico" em que poderá ocorrer, em princípio, um grande número de alofonias na fala e o "lugar" de um grande número de variações de escrita.

No que concerne à teoria da sonoridade, definimos a sílaba como uma curva que cresce (do onset) até um ponto de inflexão, o ápice silábico (o núcleo silábico), e que decresce em seguida até um ponto autorizado na língua (coda). A parte inicial e crescente da curva corresponde ao onset, o ponto de inflexão superior corresponde ao núcleo silábico, a parte final decrescente corresponde à coda. Esta última é uma posição consonantal pouco favorável às distinções fonológicas e o "locus", portanto, de grande instabilidade estrutural.

A fim de operacionar a noção de sonoridade, propomos a escala de sonoridade que segue. ${ }^{3}$

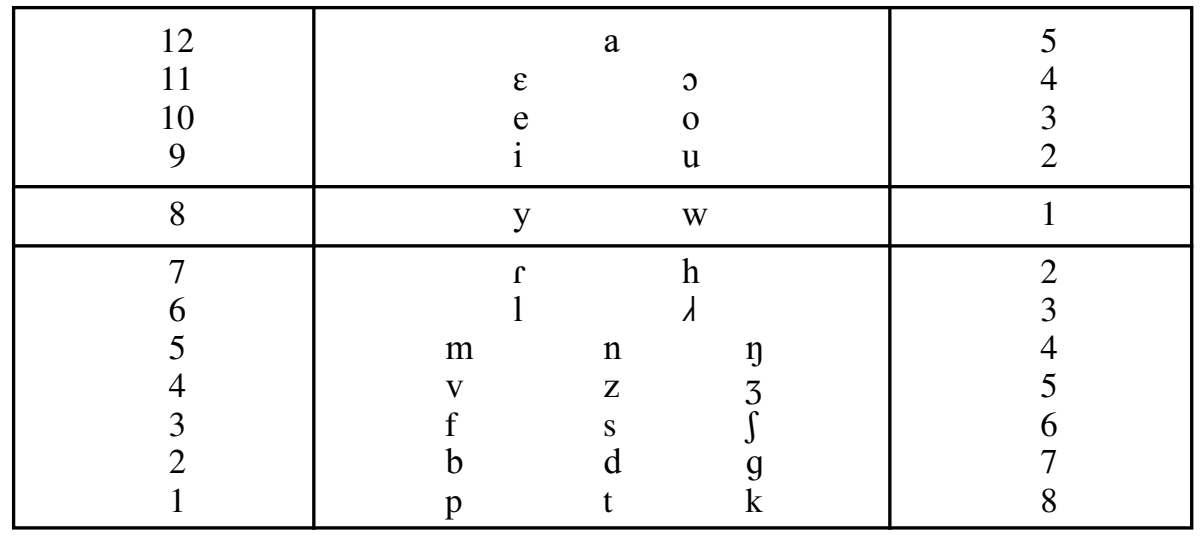


A escala numérica da esquerda indica a ordem de sonorização, o grau de abertura, crescente de baixo para cima. A escala da direita indica a ordem de força, crescente de baixo para cima entre as vogais (de 01 a 05) e de cima para baixo entre as consoantes (de 01 a 08). As consoantes de abertura menor são, pois, as consoantes mais fortes e as vogais de abertura menor são, inversamente, as menos fortes. Do ponto de vista articulatório, podemos dizer que o ótimo para as consoantes é a abertura mínima; para as vogais, ao contrário, é a abertura máxima. Esta escala de sonoridade respeita, na ordem, os diversos graus de sonoridade dos fonemas. Esta escala propõe, ainda, que existe uma ordem de força entre os fonemas, as consoantes de um lado, as vogais de outro. Assim, por hipótese, as consoantes nãocontínuas surdas $(/ \mathrm{p} /, / \mathrm{t} / \mathrm{e} / \mathrm{k} /$ ) são, do ponto de vista da sonoridade (01 da esquerda), mais baixas na escala que as correspondentes sonoras (02 da esquerda). Em contrapartida, estas últimas serão menos fortes e menos estáveis ( 07 da direita) que as primeiras (08 da direita). Entre as vogais, os fonemas / e / e / o / são mais altas na escala (10 da esquerda) que as vogais / i / e / u / (09 da esquerda). Em contrapartida, estas últimas são menos fortes e menos estáveis (02 da direita) que as primeiras ( 03 da direita). Nesta escala, o nível 08 da esquerda indica os glides (semivogais ou semiconsoantes), o limite entre as duas classes maiores: as consoantes (de 01 a 07 ) e as vogais (de 09 a 12). Como elementos limítrofes, os glides podem ser considerados, do ponto de vista funcional, seja como consoantes, seja como vogais. Em português, as consoantes são os elementos que podem aparecer nas posições de onset ou de coda. As vogais são os elementos que aparecem na posição de núcleo.

Juntamente com esta escala, estamos propondo um princípio geral que controla as condições de co-ocorrência de segmentos na sílaba, o Princípio do Contraste (PC) - uma versão modificada do Princípio do Contorno Obrigatório (OCP), conforme proposto por Encrevé (1988). Este princípio está na base das restrições ou das regras fonotáticas entre os segmentos numa seqüência segmental na sílaba e possibilita a boa formação fonológica que parte da 
necessidade de uma diferença sonora entre os segmentos adjacentes. Não sendo absoluta a distância entre dois segmentos adjacentes quaisquer, uma vez que esta distância depende da natureza de cada elemento e de sua posição na escala de sonoridade, postula-se a existência de uma escala de distâncias entre os pares de segmentos. Com esta noção de distância relativa, introduziremos a noção de escala de canonicidade, definida pelas distâncias entre elementos adjacentes e indo de uma zona ótima a uma zona minima de distância.

No sentido de melhor compreender a noção de distância entre dois elementos adjacentes e os fenômenos fonológicos a ela relacionados, estamos propondo duas escalas: uma escala numérica de distanciamentos entre os elementos; outra escala de estabilidade das estruturas resultantes. Dessa maneira, defendemos que, numa posição silábica, uma distância maior entre dois segmentos adjacentes produz, como resultado, uma estrutura mais estável na língua que uma distância menor.

Com a ajuda de exemplos, analisemos esta proposta, utilizando a escala numérica apresentada. Sejam dadas as seqüências segmentais "ps" e "pl" na posição de onset silábico. O fonema / p / tem um índice de sonoridade 01; o / s / tem 03 e o / 1 / tem 06. As seqüências "ps" e "pl" terão as distâncias de 2 e 5 , respectivamente. Assim, a seqüência "pl" será considerada, por hipótese, mais estável na língua que a seqüência "ps", pois a diferença entre os dois segmentos em "pl" é maior que a distância entre os elementos em "ps". Dessa maneira, postulamos que a estrutura "ps", mais instável do que a estrutura "pl", pode, teoricamente, se constituir num "locus" mais freqüente de variações que a estrutura "pl". Podemos, ainda, supor que a seqüência "pl" será mais freqüentemente escolhida pelas línguas que a seqüência "ps". Mesmo numa língua que aceite as duas seqüências em questão, podemos propor como hipótese que a estrutura "pl" será mais freqüente que a estrutura "ps", isto é, que haverá mais palavras que contenham a seqüência "pl" do que "ps". Seguindo o mesmo raciocínio, pode-se, ainda, propor como hipótese 
que, para cada dupla apresentada na lista a seguir, a segunda seqüência de fonemas é, em princípio, mais freqüentemente escolhida pelas línguas, e mais freqüente nas línguas que têm as duas seqüências.

$$
\begin{aligned}
& \text { "pt" - "ps" } \\
& \text { "ps" - "pr" } \\
& \text { "gn" - "gl" } \\
& \text { "ts" - "tm" } \\
& \text { "tm" - "tr" } \\
& \text { "ks" - "kl" }
\end{aligned}
$$

Finalmente, pode-se adiantar que as seqüências da esquerda em cada par são um "locus" mais freqüente de variações na língua que as seqüências da direita. Assim, por exemplo, processos de reconstrução que operam na direção das estruturas mais estáveis (como a epêntese, os apagamentos) deverão ser mais freqüentes com as seqüências da esquerda.

$\mathrm{Na}$ classe das vogais, pode-se propor também, por hipótese, que as seqüências [ya] e [wa] são, em razão de distâncias maiores entre os elementos, mais estáveis nas línguas que as seqüências [yi] e [wi]. Como entre as vogais "e" e "a" a distância é muito pequena (02 segundo a escala), ainda por hipótese, supomos que a tendência das línguas deva ser de as considerar como pertencentes a dois núcleos silábicos diferentes. Isto implica que estes dois elementos não apresentam um grau de contraste suficiente para pertencerem ambos a uma mesma posição e a uma mesma sílaba.

Nesse modelo, é o princípio do contraste que dá conta de todas estas diferenças e que está na base das escalas de canonicidade e de estabilidade silábica. Definiremos este princípio como segue: "numa linha melódica qualquer, para pertencerem a uma mesma unidade hierárquica, dois autosegmentos adjacentes "a" e "b" devem fazer contraste, sendo estes contrastes medidos por parâmetros particulares a cada língua." 
Uma conseqüência do princípio do contraste, tal como o apresentamos, é que dois autosegmentos adjacentes idênticos ou muito próximos em grau de sonoridade devem ser interpretados como pertencendo a duas unidades diferentes. Se, contudo, estes dois segmentos adjacentes pertencem à mesma unidade, eles serão, por princípio, considerados como estáveis na língua. Cada língua terá, pois, a partir do princípio do contraste e de uma escala de sonoridade, seus próprios parâmetros e suas próprias maneiras de definir estes contrastes em termos de seqüências aceitas e de seqüências rejeitadas. As seqüências aceitas por uma língua e rejeitadas pelo princípio de boa formação fonológica (se isto existe) são, por hipótese, candidatas prováveis à reestruturação, pela inserção e/ou apagamento de elementos, sempre numa perspectiva de se aproximar das estruturas mais estáveis e mais canônicas na língua em questão. O princípio do contraste indica as condições segundo as quais as estruturas fonológicas tendem, nas suas transformações, rumo a uma boa formação, seja no nível lexical (na silabação profunda), seja durante as transformações existentes no sistema fonológico. O resultado da aplicação deste princípio será a construção ou a reconstrução de estruturas mais regulares, mais canônicas e mais estáveis na língua.

Com o auxílio da escala de sonoridade proposta e do princípio do contraste, pode-se propor o esquema apresentado na próxima página, que define as possibilidades de co-ocorrência de segmentos em cada posição silábica em português.

$\mathrm{Na}$ primeira posição, de onset, podem aparecer, no nível fonológico, todos os traços consonantais do português, com a possibilidade de ocorrência das 19 consoantes no nível segmental ou fonético. Esta posição de onset pode, ainda, não ser preenchida segmentalmente ocasionando um vazio estrutural. ${ }^{4} \mathrm{Na}$ segunda posição do onset, podem existir, opcionalmente, duas consoantes relativamente estáveis, $\mathrm{o} / \mathrm{r} / \mathrm{e} \mathrm{o} / 1 /$, que podem aparecer após as consoantes oclusivas e após duas das fricativas (/f / e / v / ). Nesta mesma segunda posição, as consoantes / $\mathrm{m} /, / \mathrm{n} / \mathrm{e} / \mathrm{s} /$ são 


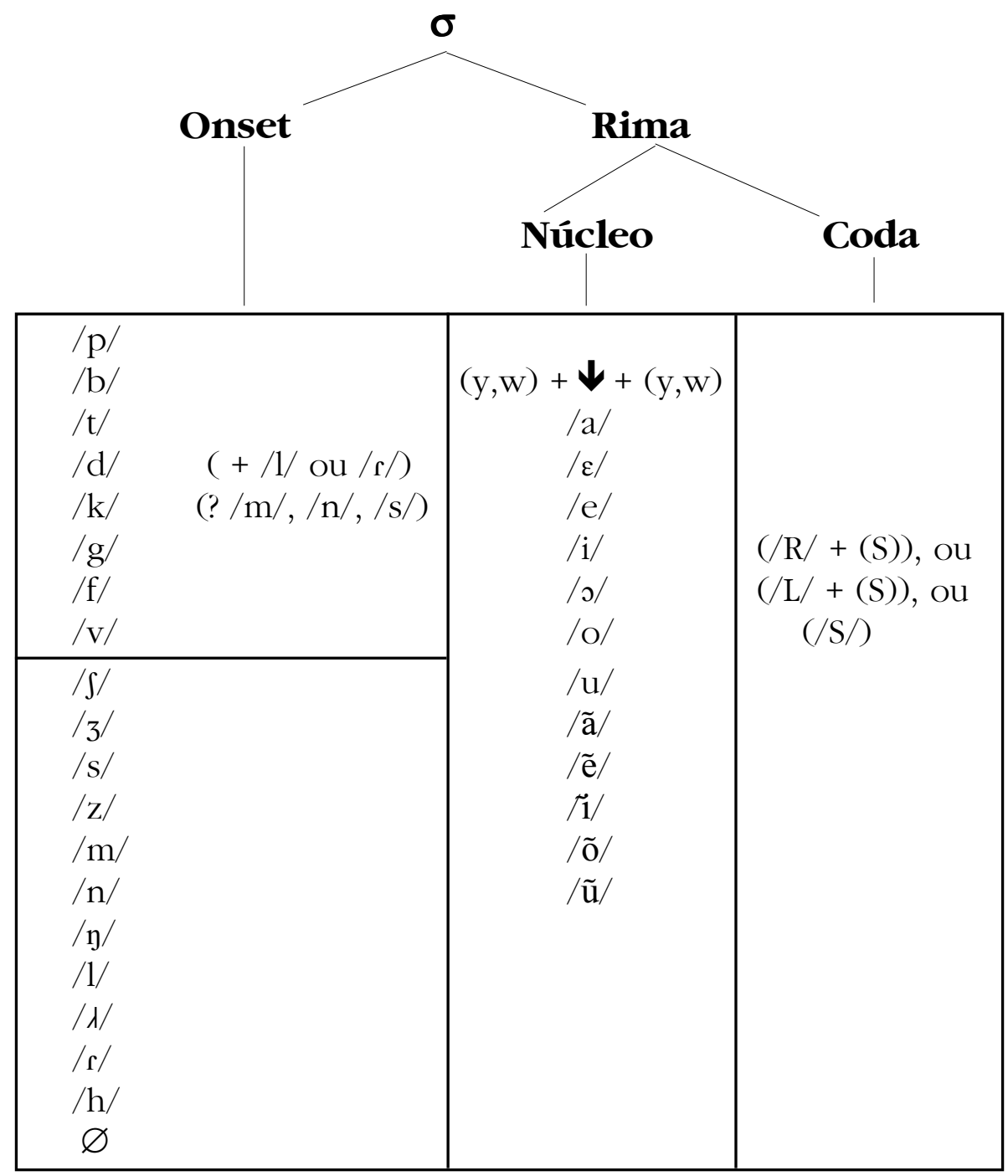

possíveis nos contextos de língua formal, mas, de maneira geral, elas indicam pontos instáveis nos quais as inserções vocálicas têm por resultado a criação de estruturas mais canônicas (['hit Jimu]). Nestes casos, as inserções vocálicas produzem distâncias maiores entre os 
elementos, além de produzir uma ressilabação reconstituindo sílabas mais canônicas, isto é, mais conformes com o padrão da língua.

Na posição de núcleo silábico, existem doze vogais possíveis, sete orais e cinco nasais. Ainda no núcleo, existem, opcionalmente, os glides (semivogais) / y / e / w / que entram na constituição dos ditongos e tritongos. Os glides que formam ditongos decrescentes são mais estáveis que os glides dos ditongos crescentes, podendo estes últimos serem ressilabados como núcleos de uma nova sílaba, constituindo-se a vogal seguinte, no caso, numa sílaba com onset nulo ou vazio.

Na posição de coda, existem, opcionalmente, três possíveis fonemas para a primeira posição: /R/, /L/ e /S/. Utilizamos letras maiúsculas para representar estes elementos, pois eles são "arquifonemas"; 5 isto significa que eles podem não apresentar, de uma maneira constante e estável na língua, os traços distintivos 'ponto de articulação' e 'fonte' (vozeamento), isto é, pode haver uma neutralização desses traços. Em outros termos, seus traços fonéticos 'ponto' e 'fonte' serão especificados segundo cada dialeto. $\mathrm{Na}$ segunda posição, dentro da coda (depois de /R/ e /L/), existe, opcionalmente, um só elemento, o fonema / S /.

É importante salientar que não existe unanimidade de posição, especialmente, no que se refere aos elementos coda em português. Certamente / R / e / S / são sempre considerados como coda em todas as análises. A realização fonética dessas codas será variável em função do contexto estrutural seguinte e/ou em função do dialeto. $\mathrm{O} / \mathrm{L}$ / tem mais de uma realização fonética, de acordo com a distribuição dialetal. A realização fonética mais geral faz desse elemento uma semivogal ([ w ]). Como existe a sua realização, em alguns dialetos, também como consoante ( [ 1 ] ou [ r ] ), pode-se considerá-lo como coda. As várias realizações fonéticas se explicariam, por hipótese, como decorrência da instabilidade ou enfraquecimento da posição de coda em português. ${ }^{6}$

$\mathrm{Na}$ análise que será desenvolvida na seqüência deste artigo, estaremos considerando como coda, pois, apenas os elementos / R /, / S / e / L. 


\section{APLICAÇÃO DA TEORIA NA ANÁLISE DO PORTUGUÊS}

A teoria apresentada serve de base para a análise dos tipos silábicos em português e para a avaliação do desempenho dos aprendizes em leitura e em produção de textos. É interessante observar que a sílaba CV, considerada a estrutura mais canônica, é também a sílaba mais freqüente na língua. De fato, em textos variados de adultos e de crianças, esta sílaba CV apresenta altos índices de freqüência, em torno de 50\%. Os outros tipos, menos canônicos, são também menos freqüentes. A sílaba CVC, no mesmo material analisado, ${ }^{7}$ tem uma freqüência aproximada de 18\%. A sílaba $\mathrm{V}$ apresenta um freqüência em torno de 10\%, seguida de VC, em torno de 5\%, de CCv e CVsV, ambos em torno de 4\%. Na seqüência vem a sílaba CVs com aproximadamente, 3\%. Pelo que se percebe, a freqüência dos tipos silábicos em português pode encontrar uma boa explicação na teoria apresentada.

Hipóteses de trabalho podem ser formuladas no sentido de se testar a influência da canonicidade e da estabilidade ou instabilidade silábica no tempo de reconhecimento de palavras, frases e textos no momento da leitura e na ocorrência de variações de escrita na produção dos aprendizes. Considerando a canonicidade e a instabilidade das estruturas silábicas, é de se esperar que a sílaba CV seja, do ponto de vista da aprendizagem, a estrutura silábica mais fácil. Sendo a mais canônica (por isso a mais freqüente na fala), ela deve ser a sílaba que o aprendiz 'espera' encontrar nas suas primeiras abordagens da língua escrita. É de se supor, por conseqüência, que as sílabas menos canônicas sejam na língua falada um ponto fundamental de instabilidade estrutural, o que justificaria, nestes pontos, mudanças de pronúncia. Isto pode ser evidenciado nas dificuldades que as crianças apresentam quando aprendem a falar e na tendência, mesmo entre adultos, de transformar as palavras quando falam. O que estamos querendo sugerir é que muitas das transformações ocorridas na fala encontram suporte nesta teoria da canonicidade e da estabilidade. Como a escrita é a representação da 
língua falada, é de se supor que as variações de escrita dos aprendizes ocorram, de maneira mais freqüente, naqueles pontos considerados estruturalmente instáveis, pontos esses que atestam uma diferença em relação à sílaba CV, a estrutura mais canônica do português.

É, portanto, esperado, por hipótese, encontrar um número significativo de variações de escrita nos seguintes contextos, entre outros: (a) na consoante de final de sílaba (coda), especialmente no final de palavra ("falá" no lugar de "falar", "resovia" no lugar de "resolvia"); (b) na vogal sozinha, no início ou no interior de palavras ( "marelo" no lugar de "amarelo", "comprende" no lugar de "compreende"); (c.) na semivogal dos ditongos ("pexe" no lugar de "peixe", "falô" no lugar de "falou"); (d) numa segunda consoante de início de sílaba, em início ou em interior de palavras ("entou" no lugar de "entrou", "poblema" no lugar de "problema").

Como exemplo de aplicação das idéias expostas é interessante apresentar os resultados de análise experimental já realizada, ${ }^{8}$ considerando apenas a possível (era uma hipótese) instabilidade estrutural da consoante de final de sílaba (coda) em comparação com a consoante de início de sílaba (onset). Os seguintes resultados foram encontrados:

\begin{tabular}{|l|r|r|}
\hline Número de onsets no 'corpus' & 22.511 & $78 \%$ \\
\hline Número de codas no 'corpus' & 8.799 & $28 \%$ \\
\hline Número de variação de escrita em onsets & 223 & $0,99 \%$ \\
\hline Número de variação de escrita em codas & 252 & $2,86 \%$ \\
\hline
\end{tabular}

Atestada uma diferença significativa entre as taxas de ocorrência de variações de escrita em onset e em coda, estes resultados evidenciam a hipótese da instabilidade do elemento coda: as variações de escrita em coda são significativamente mais freqüentes do que em onset ( $\left.X_{1 \mathrm{dl}}^{2}=153,4 ; \mathrm{p}<0,01\right)$. 
Finalizemos essa seção. Tentamos, de maneira sucinta, apresentar algumas idéias dentro do quadro da teoria fonológica autosegmental. Optamos por descrever sobre a sílaba em português e sobre os princípios de boa formação fonológica. Mostramos a possibilidade de explicar muitas das variações ocorridas na fala e boa parte das variações de escrita dos aprendizes de língua escrita. Apresentamos também uma rápida aplicação da teoria exposta à análise e confronto de duas estruturas silábicas, a saber, CV e CVC, concluindo pela instabilidade da consoante final de estrutura CVC. Este tipo de análise pode ser ainda aplicado em experimentos que testem a instabilidade de outros elementos silábicos, como a presença de duas consoantes adjacentes (CCV), a ausência de onset (V, VC), a co-ocorrência de elementos vocálicos, nos ditongos e tritongos (Cvs, CsCs), entre outros. Estas análises ficam como um convite à investigação.

Os resultados de pesquisa mostraram que a hipótese da instabilidade de coda em português se sustém. Podemos aceitar que a posição de coda é, de fato, um ponto virtual de um número considerável de variações de escrita. Na seqüência voltaremos nosso olhar mais detalhadamente para o elemento coda. É certo que aí ocorre um número significativo de variações de escrita. O que queremos saber agora é se há diferença de comportamento entre os três tipos de coda analisados: / S /, / R / e / L /. Queremos saber também quais são os fatores estruturais e não estruturais que favorecem ou não favorecem a ocorrência dessas variações.

\section{AS BASES DO DESEMPENHO ORTOGRÁFICO}

\section{1 - A escrita como construção}

Há várias maneiras pelas quais podemos conceber o aprendizado da escrita. Na verdade, cada teoria de aprendizado irá nos conduzir para uma ou outra maneira de entender este processo. Por exemplo, seria possível dizer que o aprendizado da escrita, assim 
como qualquer outro tipo de aprendizado, é um processo que se dá de fora para dentro do aprendiz. Neste caso, o aprendiz agirá apenas como um tipo de receptáculo, no qual será derramado um conhecimento específico, no caso em questão, a escrita. Este tipo de concepção do que seja aprendizado irá nos conduzir a um tipo específico de concepção do que seja ensinar. Se é verdade que o aprendiz age como uma espécie de 'sacola', onde depositamos conhecimento, então faz sentido entender-se o ensino como um conjunto de técnicas que visam a garantir esta transferência de conhecimento, de fora para dentro. Na verdade, muitas das práticas pedagógicas ainda funcionam em termos desta concepção do que seja ensino/aprendizado. Na verdade, é exatamente isto que acontece quando estamos lidando com casos excepcionais, que são aprendidos (e ensinados) um a um, impedindo qualquer possibilidade de generalização. Isto não quer dizer, contudo, que a totalidade do processo de aprendizagem possa ser concebida nestas bases. As práticas comportamentistas seguem, no geral, esta tendência. No entanto, muito se tem feito, modernamente, para se mostrar que o aprendizado é, na verdade, um processo de construção, direcionado de dentro para fora, numa interação contínua entre o aprendiz e o seu objeto de aprendizado. Esta nova maneira de ver o aprendizado irá nos conduzir a uma concepção específica do papel do professor no processo de aprendizagem. Se o aprendiz é um elemento ativo na construção do conhecimento, o professor, por força, terá que ser um elemento auxiliar, facilitador desse processo. É nesta concepção de aprendizado que situamos nossa posição.

É preciso notar, no entanto, que o entendimento do aprendizado como uma construção admite variações. E estas variações têm a ver com aquilo que incluímos, ou não, na bagagem que o aprendiz traz para sua interação com o objeto escrita. Sem tentar detalhar estas divergências, ${ }^{9}$ digamos que nossa maneira de entender as características deste aprendiz inclua a sua competência lingüística, i.e., aquilo que ele já sabe sobre sua língua, antes de aprender a ler e escrever, enquanto falante nativo desta língua. 
Resumindo, estamos concebendo o aprendizado como um processo feito da interação do aprendiz com o objeto escrita: o aprendiz faz hipóteses sobre este objeto e filtra estas hipóteses através de seu conhecimento dos fatos da oralidade..$^{10}$ É evidente que esta interferência da oralidade no processo de construção da escrita é mais forte nas fases iniciais do processo do que nas fases finais, uma vez que aprender a escrever consiste, entre outras coisas, em se cortar as ligações que unem o código oral ao código escrito, tratando-os como códigos independentes (embora relacionáveis).

\section{2 - As bases da escrita: de código a representação}

Com base naquilo que afirmamos na seção anterior, podemos dizer que, num certo sentido, há uma tendência para que os aprendizes escrevam, nos estágios iniciais do processo, da maneira como falam, o que os deixa com uma escrita de natureza fonética. Por exemplo, quando alguém escreve palavras como bolu, sou, osa, gera em lugar de bolo, sol, onça e guerra, está fazendo, de fato, transcrição fonética, ou seja, está codificando sua fala. Note-se que as palavras acima seriam transcritas, foneticamente, de acordo com a pronúncia da região de Belo Horizonte, como [bolu], [sow] , [õsa], [geha] . Não é preciso ser nenhum foneticista para perceber que as escritas apresentadas acima se parecem muito mais com as transcrições fonéticas do que com as escritas oficiais, ortográficas, das palavras em questão. Resumindo, grafias como bolu, sou, osa e gera , que chamamos de variações de escrita, revelam que o aprendiz está mesmo considerando os fatos de sua fala, uma vez que a escrita ortográfica não poderia servir de modelo para elas. Claro está, portanto, que o objeto escrita, tal como ele é, não decide tudo.

A passagem de escritas como bolu, sou, osa e gera para bolo, sol, onça e guerra se deve ao abandono progressivo da fala como modelo único de escrita, num processo que troca uma base concreta (a fala) por uma base de natureza abstrata (a língua), i.e., que se move de uma escrita do tipo codificação para uma escrita do 
tipo representação. Por exemplo, quando se troca a escrita bolu pela escrita bolo, onde agora a mesma letra "o "representa dois sons (concretos) diferentes, [ o ] e [ u ], não se segue, e nem estamos sugerindo, que a fala tenha sido alterada de [ bolu ] para [ bolo ]. Tudo o que o aprendiz precisa conhecer é uma convenção que diz que o som [ u ], em posição final átona, se escreve com a letra "O “. E, na verdade, para a língua portuguesa não faz a menor diferença, em termos de sentido, se uma palavra como bolo é pronunciada como [ bolu ], como se faz na maior parte da região sudeste, ou como [bolo], como acontece em parte do sul do Brasil. Para a língua, portanto, [ o ] e [ u ] átonos finais são....a mesma coisa. E, se são a mesma coisa, só precisamos de uma letra para representálos. A convenção nos dá, neste caso, a letra "o".

\section{3 - As previsões sobre as codas em questão}

Dissemos acima que o aprendiz toma como base para a aquisição da escrita aquilo que ele já domina, ou seja, a oralidade. E, como se sabe, a oralidade é o locus de uma série de fenômenos que provocam alterações na composição fonética das palavras. São os chamados processos fonológicos. Assim, nem sempre a mesma escrita corresponderá à mesma fala. Vimos um exemplo acima com a palavra bolo, onde os dois casos da letra 'o' representam sons diferentes na maior parte dos dialetos brasileiros, [ o ] no primeiro caso e [ u ] no segundo. No caso das codas silábicas examinadas aqui, ocorre o mesmo fenômeno.

As codas selecionadas para nossa análise foram aquelas representadas pelas letras $\{1\},\{\mathrm{r}\}$ e $\{\mathrm{s}\}$. Vejamos cada uma delas.

A coda em $\{1\}$ ocorre em palavras como sol, mel, papel, salvar, alto , entre outras. Os três primeiros casos são particularmente interessantes para nosso argumento aqui. Note-se que nestes três casos, sol, mel e papel, a letra $\{1\}$ representa, de fato, o som $[\mathrm{w}]$, um som muito parecido com o som [ u ], exceto pelo fato de ocorrer numa coda (ao contrário do som [ u ], que nunca ocorre em 
coda). O que é interessante observar é que a mesma raiz nominal, em palavras cognatas, continua preservando a letra $\{1\}$, enquanto que o som correspondente, por sua vez, muda para [1] : solar, melado e papelada.

Assim sendo, se nossa hipótese sobre a base inicial da escrita é verdadeira, podemos esperar o seguinte:

a) Devemos encontrar registros do tipo 'sou', 'meu'e 'papeu', mas nunca 'souar', 'meuado' e 'papeuada', já que os três primeiros teriam uma justificativa fonética enquanto que os três últimos, não.

b) Devemos esperar que esta relação estreita entre a escrita e a pronúncia vá sendo diminuída (mas, não necessariamente, eliminada) à medida que o aprendiz avança em sua educação formal e exposição à escrita.

Algo semelhante pode ser esperado com relação à coda em $\{r\}$ onde este $\{r\}$ escrito pode representar um som $[h]$ ou mesmo a ausência de qualquer som. É esta possível ausência de som que vai nos interessar aqui, uma vez que ela pode conduzir a escritas onde o $\{r\}$ não seja representado.

Um exemplo disto pode ser dado pela grafia muito freqüente de infinitivos verbais sem o $\{\mathrm{r}\}$ final, como 'fala' (por falar), 'corre' (por correr), etc.

Já no caso da coda em $\{\mathrm{s}\}$ a situação é um pouco mais complexa. Podemos encontrar aí quatro situações diferentes:

1 - A coda simplesmente não é representada. Ex: coto = gosto

2 - A coda é representada em posição trocada. Ex: seta = está

3 - A coda é representada, na posição correta, mas em forma não-ortográfica. Ex: ves = vez

4 - A coda não é representada enquanto indicativo de plural. Ex: os menino_feio_.

Para efeito da nossa análise estaremos considerando, apenas, os casos do tipo 1 e 4, uma vez que os casos 2 e 3 não podem ser atribuídos à ausência da coda na fala. 
Conforme veremos na seção 5, todos estes três casos se revelaram problemáticos e deverão merecer atenção por parte dos educadores.

\section{ANÁLISE DOS CASOS}

\section{1 - Considerações metodológicas}

O corpus utilizado para esta análise é constituído por 320 redações de crianças de $1^{\mathrm{a}}$ a $8^{\mathrm{a}}$ séries do $1^{\circ}$ grau. Em cada série foram consideradas 40 redações, sendo que os fatores não-estruturais de análise foram igualmente balanceados entre os informantes. Assim, temos uma divisão igualitária entre as séries ( 40 alunos por série), sexo (160 meninos e 160 meninas), Método (160 alunos alfabetizados pelo método fônico e 160 pelo método global) e Classe (160 alunos de escolas de classes mais favorecidas e 160 alunos de escolas de classes menos favorecidas).

Foram considerados também fatores de natureza estrutural (contexto fonético, classe da palavra, posição do acento tônico, etc).

A análise quantitativa, por sua vez, foi executada com a ajuda de dois pacotes estatísticos, o programa VARBRUL, para a análise de regras variáveis (uma vez que os fatos fonéticos que podem conduzir aos problemas de escrita são de natureza variável) e o pacote SYSTAT, que foi utilizado para análises mais refinadas (Teste-T, análise de correlação, análise de variância) nos casos onde alguma dúvida de interpretação ainda permanecia. Vejamos, então, caso a caso.

\section{2 - Análise quantitativa}

\subsection{1 - Coda em / s /}

Iniciaremos nossa análise quantitativa pela coda $\mathrm{em} / \mathrm{s} /$, onde encontramos um total de 2991 casos com apenas 78 casos (3\%) de omissão de $\{s\}$ ou $\{z\}$, Os fatores considerados para a análise foram os seguintes: 


\section{FATORES ESTRUTURAIS}

1- Posição da coda

$\mathrm{I}=$ posição interna (Ex: isto, gosto, etc)

$\mathrm{M}=$ posição final monomorfêmico (Ex: mês, nariz, ananás, etc)

$\mathrm{B}=$ posição final bimorfêmico (Ex: gatos, valores, atuns)

2- Contexto Seguinte

$\mathrm{N}=$ nasais

$\mathrm{L}=$ laterais

$\mathrm{S}=$ fricativas

$\mathrm{P}=$ oclusivas labiais

$\mathrm{T}=$ oclusivas dentais e alveolares

$\mathrm{V}=$ vogais

\section{FATORES NÃO-ESTRUTURAIS}

3- Série Escolar

$1,2,3,4,5,6,7$ e 8 (para as séries do $1^{\circ}$ grau)

4- Método

$$
\begin{aligned}
& G=\text { global } \\
& F=\text { fônico }
\end{aligned}
$$

5- Classe Social

$\mathrm{B}=$ menos favorecida

$\mathrm{A}=$ mais favorecida

6- Sexo

$\mathrm{M}=$ masculino

$\mathrm{F}=$ feminino

Consideremos em primeiro lugar os dois grupos de fatores de natureza estrutural, Posição da Coda e Contexto Seguinte. No primeiro caso, Posição da Coda, onde encontramos diferenças de 
ordem fonológica (interno vs final) e morfológica (monomorfêmico vs bimorfêmico), nenhum efeito se revelou importante. Há 2\% de omissão de letra nos monomorfêmicos finais, 3\% nos bimorfêmicos finais e $3 \%$ nos internos. Portanto podemos dizer, com segurança, que esta diferença de posição da coda em / s / não interfere, positiva ou negativamente, em possíveis problemas na sua representação ortográfica. Já no caso do contexto fonológico seguinte, vamos encontrar algumas diferenças interessantes. Aqui, os contextos que favorecem a omissão da representação gráfica da coda / s / são os seguintes, em ordem decrescente (onde os pesos dos fatores são dados em termos de probabilidades, e não em termos de percentuais):

.65 : consoantes fricativas

.64 : consoante lateral

.63 : consoante nasal

.58 : pausa

Já os contextos desfavorecedores são as vogais (.49) e as consoantes oclusivas (.40). Na verdade, o efeito das vogais é, basicamente, neutro, e não desfavorecedor, uma vez que sua probabilidade de contribuição à regra se situa muito perto de .50, que é o valor médio dos intervalos entre 0.00 ( nunca acontece o fenômeno em questão) e 1.00 (sempre acontece o fenômeno em questão). O efeito favorecedor das consoantes fricativas pode ser explicado em termos articulatórios uma vez que a seqüência de duas fricativas levará sempre à crase, i.e., só uma será pronunciada. Assim sendo, as duas seqüências abaixo deverão ser pronunciadas do mesmo modo:

- Os problemas sem solução...

- Os problema sem solução....

Para os outros casos e, é claro, desconsiderando-se os casos de pausa, o que temos é uma distribuição entre elementos [+consonantal, -vocálico] (as consoantes oclusivas), que desfavorecem o fenômeno, e elementos [ $\alpha$ consonantal, +vocálico] (as 
vogais, que são neutras, e as consoantes sonorantes). De qualquer forma, este é um grupo de fatores que o programa VARBRUL selecionou como sendo 'eliminável', i.e., um grupo que como um todo não é significativo, muito embora seja possível encontraremse diferenças relativas entre seus elementos.

Se o que foi dito no parágrafo anterior é verdade, então, aparentemente, não vamos ter nenhum fator estrutural importante na preservação ou na omissão da representação gráfica da coda em / s /. Quais seriam, então, os fatores relevantes a serem considerados? Para responder a esta pergunta, passamos agora ao exame dos fatores de natureza não-estrutural.

Dos fatores não-estrutrurais considerados, Série, Classe Social, Método e Sexo, somente os dois primeiros, Série Escolar e Classe Social, se mostraram relevantes na análise da coda em / s / Com base nas diferenças e semelhanças entre as freqüências obtidas para cada uma das oito séries examinadas, acabamos por juntá-las em três grupos: no primeiro grupo deixamos apenas a $1^{\mathrm{a}}$ série do $1^{\circ}$ grau (doravante $1 \mathrm{~s} 1 \mathrm{~g}$ ), que apresentava um percentual de omissões de $10 \%$; no segundo grupo a 2 s1g (3\%), a $3 s 1 g$ (5\%), a $4 \mathrm{~s} 1 \mathrm{~g}(2 \%)$ e a $5 \mathrm{~s} 1 \mathrm{~g}(4 \%)$; e no terceiro grupo juntamos a $6 \mathrm{~s} 1 \mathrm{~g}$ (1\%), a $7 \mathrm{~s} 1 \mathrm{~g}(1 \%) \mathrm{e}$ a $8 \mathrm{~s} 1 \mathrm{~g}(2 \%)$. E o resultado probabilístico encontrado foi o seguinte:

$\begin{array}{ll}\text { Grupo I } & : .85 \\ \text { Grupo II } & : .66 \\ \text { Grupo III } & : .35\end{array}$

Os resultados aqui são muito evidentes e querem dizer que a omissão gráfica da coda em / s / é um problema que tende a desaparecer à medida que o aprendiz avança em sua educação formal. Na verdade, esta omissão é fortemente desfavorecida nas três últimas séries do $1^{\circ}$ grau. Mas há ainda um outro ponto a ser considerado: este grupo de fatores, como um todo, foi selecionado pelo VARBRUL como sendo um grupo significativo, independentemente de seus valores internos. 
Algo semelhante ocorreu com o grupo de fatores Classe Social. Aqui, nota-se um favorecimento da omissão gráfica da coda em / s / por parte das classes menos favorecidas, com uma probabilidade de .67, enquanto que as classes mais favorecidas desfavorecem esta omissão, com uma probabilidade de .33 . Novamente, o grupo de fatores, como um todo, foi selecionado pelo VARBRUL como sendo significativo para o fenômeno em questão.

Por outro lado, os grupos de fatores Sexo e Método não só foram apontados pelo VARBRUL como sendo insignificantes para o problema em questão, como também apresentaram valores relativos internos que são quase idênticos. Por exemplo, no caso de Sexo, o efeito do fator Masculino é .50, enquanto que o efeito do fator Feminino é .49, i.e., são ambos neutros. No caso de grupo de fatores Método (global x fônico), temos algo parecido, com .52 para o Método Global e .47 para o Método Fônico, i.e., ambos muito próximos de .50 , que é o valor neutro.

Resumindo, este primeiro caso é, portanto, sensível a Série Escolar e Classe Social. Antes de tecermos quaisquer considerações de natureza pedagógica aqui, vamos examinar as outras duas codas, $\mathrm{em} / 1 / \mathrm{e} \mathrm{em} / \mathrm{r} /$, para vermos se elas também são sensíveis aos mesmos fatores.

\subsection{2 - Coda em / r /}

Os casos de coda em / $\mathrm{r}$ / foram separados, inicialmente, em três grupos distintos:

Grupo 1: / r / interno, como em corta, parta, morde. Grupo 2: / $\mathrm{r}$ / final em nominais, como em mar, cantor, revólver. Grupo 3: / r / final em verbos, como em cantar, ler, dormir.

O Grupo 1 foi descartado por não apresentar uma variação de escrita sequer de omissão do $\{\mathrm{r}\}$ no corpus examinado. O mesmo destino foi dado ao Grupo 2, onde houve apenas 1 caso de omissão de 
\{r $\}$ num total de 211 casos. Restaram apenas os casos do Grupo 3, onde foram considerados 1535 verbos terminados em $\{\mathrm{r}\}$, com 57 omissões. É bom notar que este caso inviabilizou o estudo do acento de força e do tipo de palavra, já que no Grupo 3 todos os casos apresentam o / r / em sílaba tônica e em palavras oxítonas.

Os grupos de fatores considerados foram, então, os seguintes: Série Escolar; Método de Ensino; Classe Social e Sexo. Como se pode observar, todos estes fatores são de natureza não-estrutural, e todos eles se mostraram estatisticamente significativos. Não é de se espantar que nenhum efeito estrutural apareça neste caso, uma vez que a eliminação de / r / em posição final de verbos é um processo bastante antigo no português, já salientado no séc. XVI nos trabalhos de Gil Vicente. Assim sendo, é natural que os condicionamentos estruturais já tenham sido esgotados e, portanto, desaparecido de cena.

Os resultados probabilísticos obtidos para os fatores em questão foram os seguintes:

Série Escolar

$$
\begin{array}{ll}
1=.86 & 5=.55 \\
2=.74 & 6=.38 \\
3=.42 & 7=.53 \\
4=.63 & 8=.36
\end{array}
$$

Como se pode ver aqui, o resultado por série é bastante previsível: nas duas séries iniciais há um favorecimento de escritas do tipo 'come' (comer) e 'fala' (falar), enquanto que nas outras séries há ou um desfavorecimento destas grafias ou um efeito neutro. Estes números mostram que o tempo de exposição à escrita, na escola formal, contribui para que a relação forte que se faz entre a oralidade e a escrita vá sendo atenuada à medida que o tempo vai passando. Nas séries finais do primeiro grau a tendência é a de se tratar a fala e a escrita como dois códigos independentes.

Método de Ensino

Global: $\quad .59$

Fônico: $\quad .43$ 
Aqui existe um efeito diferenciado entre os dois métodos, muito embora este efeito não seja dos maiores (i.e., nos dois casos os resultados probabilísticos se afastam pouco de .50). Uma explicação que pode ser dada para este caso é em termos da 'artificialidade' com que se trabalha o método fônico, na maioria das vezes, produzindo-se uma fala, de certa forma, artificial. E nesta 'artificialidade' fica muito mais fácil preservar-se uma relação direta entre som e letra. Por exemplo, se a professora dita coisas como 'leitê', em vez de 'leiti', fica mais fácil escrever-se leite. Contudo, a pronúncia 'leitê' é, sem dúvida, bastante artificial na maioria das regiões do Brasil.

Classe Social

Baixa: .66

Alta: $\quad .33$

Este é um caso bastante interessante. O que ele nos mostra é que quanto mais recursos pedagógicos, em sala e/ou em casa, uma criança tem à sua disposição, mais facilidade ela terá para aprender. No caso dos / r /'s finais dos verbos, não há diferenças entre os dialetos sociais: nos dois casos o / $\mathrm{r}$ / é fortemente eliminado na fala. Assim sendo, a única explicação possível para o pior desempenho por parte das crianças de classes desfavorecidas fica por conta dos recursos à disposição, que são certamente menores do que aqueles à disposição das crianças das classes mais favorecidas.

Sexo

Meninos: .64

Meninas: .37

Notamos aqui um desempenho sensivelmente melhor por parte das meninas. Por quê? Não podemos dizer, simplesmente, que as meninas são cognitivamente superiores aos meninos. Isto seria, 
no mínimo, inconseqüente. O que acontece aqui é o que acontece com todos os fenômenos lingüísticos sensíveis a classe social: as mulheres/meninas são mais atentas do que os homens/meninos ao prestígio. Isto significa que elas abraçarão mais rapidamente as marcas de prestígio, mas significa também que elas reagirão mais fortemente a qualquer fenômeno estigmatizado. Este efeito aparece praticamente em todos os estudos sociolingüísticos feitos até hoje.

\subsection{3 - Coda em / I /}

Os casos de coda em / 1/ são aqueles onde o travamento silábico se dá pelo fonema $/ 1 /$, tanto no interior quanto no final das palavras, como em 'selva' e 'mel', respectivamente. É importante observar que não estamos considerando aqui nenhum caso onde o fonema / 1 / se situa no início de uma sílaba, como em 'lado' e 'salada', por exemplo. E a razão para não considerarmos estes casos é simples: se estamos supondo que as variações de escrita se dão, em grande parte, por causa de processos fonológicos que ocorrem na oralidade, então é de se supor que casos como 'selva' possam aparecer escritos como 'seuva', mas não que casos como 'salada' possam ser escritos como 'sauada', já que esta grafia não teria nenhum respaldo na oralidade. $\mathrm{E}$, de fato, todos os casos de variações de escrita se deram na posição de coda, e nunca na posição de onset.

Nos dados examinados encontramos um total de 332 casos de / 1 / em coda, sendo que 21 deles apareceram escritos com a letra $\{\mathrm{u}\}$ em vez da letra $\{1\}$. Os grupos de fatores considerados na análise foram os seguintes:

Estruturais:

- Posição do / 1 / (interna ou final)

- Tonicidade (átono ou tônico)

- Vogal precedente (a, e, i, o) 
Não-Estruturais:

- Série Escolar (de Primeira à Oitava)

- Método de Ensino (Global ou Fônico)

- Classe Social (Favorecida e Desfavorecida)

- Sexo (Masculino e Feminino)

Os resultados probabilísticos obtidos para os fatores de cada grupo foram os seguintes:

Estruturais:

- Posição Interna: .71 Posição Final: .20

- Átonos: .52 Tônicos: .48

- Vogais Precedentes: i: .91 ; e: .91 ; a: .40 ; o: .39

Não-Estruturais:

- Série: $\quad$ Primeira: .97; Segunda + Terceira + Quarta: .86;

Quinta: .53; Sexta: .32; Sétima: 17 e Oitava: .29

- Método de Ensino: Global: .42 ; Fônico: .57

- Classe Social: Desfavorecida: .69 ; Favorecida: 36

- Sexo: Masculino: .77 ; Feminino: .22

Nem todos os grupos de fatores listados acima se mostraram significativos. Na verdade, dois deles, Tonicidade e Método de Ensino, foram removidos pelo programa VARBRUL como não significativos. Todos os outros grupos de fatores foram considerados como sendo estatisticamente significativos e, portanto, serão comentados em seguida.

Como interpretar os resultados para Posição, onde a Posição Final se mostrou menos problemática do que a Posição Interna? Nossa hipótese aqui é a de que o fonema / 1 / em posição final, onde é pronunciado como [ w ] (e, portanto, facilmente representado pela letra 'u' ), seja mais facilmente preservado com a letra $\{1\}$ pelo fato de alternar com o som [1] em palavras cognatas. Por exemplo, a palavra 'sol', que é pronunciada como [ sow ], tem como cognatos 
palavras como 'solar' e 'ensolarado', onde a letra $\{1\}$ soa como [ 1 ], e não como [ w ]. Assim sendo, fica relativamente fácil recuperarse a grafia oficial, uma vez que em casos como 'solar', por exemplo, nunca teremos o som [ w ]. Já na posição interna, não há como saber se o som [w ] deve ser representado como $\{1\}$ ou como $\{\mathrm{u}\}$. É o que temos, por exemplo, em palavras como 'calda' x 'cauda', ou 'alto' x 'auto', que são pronunciadas do mesmo modo e escritas de maneira diferente. Em resumo, nossa hipótese é que a morfologia da língua falada pode nos ajudar a recuperar a grafia oficial de casos que são potencialmente problemáticos.

Como interpretar, agora, os resultados para Vogal Precedente? Há uma clara oposição entre vogais anteriores, / e / e / i /, que favorecem as escritas em $\{\mathrm{u}\}$, e as vogais posteriores, / a / e / o /, que inibem a escrita em $\{\mathrm{u}\}$ (favorecendo, portanto, as escritas em $\{1\}$ ). Contudo, a motivação fonética subjacente a este fato é, ainda, uma incógnita para nós. Na falta de uma explicação interessante, preferimos deixar o problema em suspenso.

Já com relação aos fatores não-estruturais que se mostraram significativos, Série Escolar, Classe Social e Sexo, não temos aqui nenhuma novidade. Com relação a Série Escolar, há, como já observamos anteriormente nos casos de / $\mathrm{r} / \mathrm{e}$ de / s /, uma clara oposição entre a Primeira Série e as outras séries da primeira metade do primeiro grau. Em seguida podemos observar uma oposição entre a primeira metade e a segunda metade do primeiro grau. Ou seja, quanto mais tempo se expõe o aprendiz à educação formal, mais possibilidades ele tem de fazer a separação entre os códigos oral e escrito.

Com relação a Classe Social, os resultados se repetem aqui: os que têm mais recursos à sua disposição para enriquecer sua educação formal acabam tendo mais sucesso no aprendizado. E com relação a Sexo, podemos ver, novamente, as meninas como sendo os aprendizes mais atentos à norma.

Conforme pudemos notar nos três casos examinados, Série Escolar e Classe Social são os efeitos significativos recorrentes em 
todos eles. Podemos nos perguntar, então, qual destes dois efeitos tem mais peso. Para responder a esta pergunta fizemos mais alguns testes estatísticos, com os seguintes:

\section{a) Análise de Variância}

Comparando-se os F-ratio para Série $(7.408,7 \mathrm{df})$ e Classe Social $(0.351,1 \mathrm{df})$ podemos concluir que o efeito de Série é mais forte do que o efeito de Classe Social. O F-ratio para Série está acima do valor esperado para um nível de significância de .05, que deveria ser $>5.59$.

\section{b) Desvio Padrão}

O desvio padrão de Série Escolar é de 2.160, enquanto que o de Classe Social é de apenas 0.493 , indicando que o maior desvio da média pertence ao primeiro.

\section{c) Análise de Correlação}

As correlações mais fortes envolvem o grupo de fatores Série Escolar. Na verdade, o valor mais alto encontrado é de 0.118, para a correlação entre Série e Método. Todos os outros valores são menores do que este.

\section{CONCLUINDO}

A análise apresentada sugere alguns pontos bastante óbvios. Em primeiro lugar, fica claro que o processo de aquisição da escrita é intermediado por fatores de natureza estrutural e não-estrutural.

Os fatores estruturais refletem a interferência da estrutura da fala, bem como os processos aos quais a fala está sujeita, na aquisição da escrita. De uma certa forma, podemos dizer que a estrutura da oralidade molda o processo de aquisição da escrita, provocando as variações de escrita que podemos encontrar.

O caso que procuramos destacar aqui tem a ver com a estruturação da sílaba. A partir da estrutura silábica pudemos mostrar 
quais são os pontos de instabilidade na fala (a posição de coda) e quais as conseqüências disso em termos da exposição destes pontos a processos fonológicos. E, se é verdade que a oralidade interfere na escrita, que é tomada, inicialmente, como uma codificação da fala, então podemos prever com bastante precisão onde é que as variações de escrita irão ocorrer mais fortemente. Mas, observe-se, com isto estamos dizendo que as letras, em si mesmas, pouco ou nada têm a ver com as variações de escrita.

Evidentemente que os resultados apresentados aqui têm algumas implicações pedagógicas. A mais óbvia delas vai na direção de se propor uma prática onde se parta do conhecimento que o aprendiz já tem de sua própria língua (falada) e se trate a aquisição da escrita como um processo (e não como a simples transferência de um produto final, que o professor já tem e que o aprendiz (ainda) não tem). Em segundo lugar, estamos sugerindo que o material didático a ser utilizado em sala de aula deva ser estruturado em termos dos fatos da fala. Ou seja, nossa sugestão é a de que se utilize, primeiro, aquelas estruturas que possam se comportar mais facilmente como elementos a serem codificados, deixando-se as relações de pura representação para os estágios finais.

Finalmente, é preciso que a escola, de modo geral, esteja atenta para as implicações que os resultados obtidos para Série Escolar e Classe Social possam sugerir. É preciso investir mais onde se tem menos.

\section{NOTAS}

${ }^{1}$ O que estamos chamando de "variações de escrita" corresponde aos termos "erro"- entre aspas (Oliveira, M.A. \& Nascimento M., 1990) e "variações ortográficas" (Alvarenga, D., 1995). O termo aqui utilizado pretende evitar dois inconvenientes: (a) o conceito de valor presente na palavra "erro", mesmo com aspas; (b) o incômodo de pensar que a norma ortográfica admite variação.

${ }^{2}$ Segundo Encrevé, P. (1988), esse nível de posições puras é o esqueleto fonológico que representa o número de lugares potenciais para a realização dos segmentos fonéticos. 
${ }^{3}$ Esta escala é uma adaptação para o português a partir da que Selkirk (1984) sugeriu para o inglês.

${ }^{4} \mathrm{O}$ conceito de vazio estrutural está associado ao conceito de posição pura (Encrevé, 1988) e desempenha na teoria defendida um papel importante, pois é a base para se supor uma instabilidade cognitiva todas as vezes que uma sílaba se apresenta foneticamente sem nada na posição de onset. Essa necessidade cognitiva de um onset preenchido explicaria, por exemplo, fenômenos de ligação numa seqüência do tipo [a'zazas], na qual a sílaba "a" de "asas" estaria apresentando um 'vazio' estrutural.

5 Arquifonema aqui está sendo usado conforme conceito exposto por Mattoso (1970).

${ }^{6}$ É comum encontrar especificado entre as codas um elemento nasal (Alvarenga, 1993). No entanto, esse elemento pode, com boas razões, ser analisado como traço de nasalidade da vogal. Na verdade, não há nenhuma especificação do traço 'ponto de articulação' neste caso, o que indicaria a ausência do traço 'consoante' nessa nasalidade: ela seria sempre, em qualquer dialeto, realizada foneticamente como traço de nasalidade da vogal. Não estamos, pois, considerando o elemento nasal representado pelas letras $\{n\}$ e $\{m\}$ como coda. Para um estudo dessa nasalidade, ver dissertação de Mestrado de Alkimin, 1995.

7 Estes dados estatísticos foram retirados de Alvarenga (1993). 'C' é consoante, 'V' é vogal e 's' é semivogal.

8 Alvarenga (1993), análise realizada num 'corpus' de 320 textos de alunos, distribuídos em número igual pelas séries escolares da escola fundamental.

${ }^{9}$ O leitor interessado poderá consultar Oliveira \& Nascimento, 1990.

${ }^{10}$ Cf. Kato, 1986, cap.1.

\section{REFERÊNCIAS BIBLIOGRÁFICAS}

ALKMIM, H. R. HERRAR É UMANO: Uma visão lingüística dos desvios ortográficos da nasalidade vocálica. Dissertação de Mestrado defendida FALE/UFMG, Belo Horizonte, 1995.

ALVARENGA, D. Variations orthographiques, temps d'identification et apprentisage de la langue écrite portugaise: une approche phono-cognitive. Tese de doutorado defendida na Universidade de Paris VIII, 1993.

ALVARENGA, D. Análise de Variações Ortográficas. In: Presença Pedagógica, n⿳o 2, editora Dimensão, 1995. 
CLEMENTS, G.N.,\& KEYSER, S.J. CV phonology, a generative theory of syllable. Cambridge Mass.: MIT Press, 1983.

ENCREVÉ, P. La liaison avec et sans enchaînement. Phonologie tridimentionnelle et usages du français. Paris: Seuil, 1988.

FUDGE, E.C. Syllables. Journal of linguistics, 5, 253-286, 1969.

GOLDSMiTH, J.A. Autosegmental \& Metrical Phonology. Oxford, Cambridge: Basil Blackwell, 1990.

HOOPER, J.B. An Introduction to Natural Generative Phonology. New York, San Francisco, London: Academic Press, 1976.

KATO M.A. No Mundo da Escrita - Uma Perspectiva Psicolingüistica. São Paulo, Editora Ática, 1986.

KAYE, J.D. \& LOWEnSTAMm, J. De la syllabicité. In: F. Dell, D.Hirst, \& J.R. Vergnaud. Forme sonore du langage. Structure des représentations en phonologie. Paris: Hermamm, p.123-159, 1984.

LOWENSTAMM, J. On the maximal cluster approach to syllable structure, Linguistic Inquiry, 12 (4), 575-604, 1981.

MATTOSO-CÂMARA, J. A Estrutura da Lingua Portuguesa. Petrópolis: Vozes, 1970.

OLIVEIRA, M.A. \& NASCIMENTO, M. Da análise de erros aos mecanismos envolvidos na aprendizagem da escrita. Educação em Revista, Faculdade de Educação da UFMG, no 12, p.33-43, 1990.

SELKIRK, E. On the major class features and syllable theory. In: M.Aronoff \& R.T. Oehrle (eds). Language Sound Structure. Cambridge, Mass.: MIT Press, p.107-136, 1984. 